\title{
Determination of Lactoferrin in Camel Milk by Ultrahigh-Performance Liquid Chromatography-Tandem Mass Spectrometry Using an Isotope-Labeled Winged Peptide as Internal Standard
}

\author{
$\mathrm{Xia} \mathrm{Li}^{1}$, Zengmei Li ${ }^{1}$, Enmin $\mathrm{Xu}{ }^{2}$, Ling Chen ${ }^{2}$, Hua Feng ${ }^{1}$, Lu Chen ${ }^{1}$, Ligang Deng ${ }^{1, *}$ and \\ Dongliang Guo ${ }^{1, *}$ \\ 1 Institute of Agricultural Quality Standards and Testing Technology Research, Shandong Academy of \\ Agricultural Sciences, 202 Gongyebeilu Road, Jinan 250100, Shandong Province, China; \\ Lisa-fsd@163.com (X.L.); lizengmei78@163.com (Z.L.); wangjialinmm@163.com (H.F.); \\ chenludemail@163.com (L.C.) \\ 2 Shandong Veterinary Drug Quality Inspection Institute, 68 Huaicun Street, Jinan, Shandong Province, China; \\ xuenm@126.com (E.X.); 13708935340@163.com (L.C.) \\ * Correspondence: deng_ligang@163.com (L.D.); gd198989@163.com (D.G.); Tel.: +86-531-66659007 (L.D.); \\ +86-531-66658325 (D.G.); Fax: +86-531-66659007 (L.D.); +86-531-66658325 (D.G.)
}

Received: 29 October 2019; Accepted: 16 November 2019; Published: 19 November 2019

\begin{abstract}
An ultrahigh-performance liquid chromatography-tandem mass spectrometry method was developed and validated for the determination of lactoferrin in camel milk based on the signature peptide. The camel lactoferrin was purified by heparin affinity chromatography and then used to screen tryptic signature peptides. The signature peptide was selected on the basis of sequence database search and identified from the tryptic hydrolysates of purified camel lactoferrin by ultrahigh-performance liquid chromatography and quadrupole time-of-flight tandem mass spectrometry. The pretreatment procedures included the addition of isotope-labeled winged peptide and the disposal of lipids and caseins followed by an enzymatic digestion with trypsin. Analytes were separated on an Acquity UPLC BEH 300 C18 column and then detected on a triple-quadrupole mass spectrometer in $7 \mathrm{~min}$. The limits of detection and quantification were $3.8 \mathrm{mg} \mathrm{kg}^{-1}$ and $11 \mathrm{mg} \mathrm{kg}^{-1}$, respectively. The recoveries ranged from $74.5 \%$ to $103.6 \%$, with relative standard deviations below $7.7 \%$. The validated method was applied to determine the lactoferrin in ten samples collected from Xinjiang Province.
\end{abstract}

Keywords: lactoferrin; camel milk; ultrahigh-performance liquid chromatography-tandem mass spectrometry; heparin affinity chromatography

\section{Introduction}

Lactoferrin is an iron-binding glycoprotein that was first identified in 1939 in bovine milk [1], and in 1960 it was isolated from human milk by Johannson [2]. It belongs to the family of transferrins, together with serum transferrin, ovotransferrin, and melanotransferrin [3]. The molecular weight of lactoferrin is about $80 \mathrm{kDa}$, and it consists of a single polypeptide chain folded into two globular lobes with the ability to bind two iron atoms [4,5]. Lactoferrin plays an important role in innate defense and exhibits multifunctional activities, including maintaining iron levels, as well as antimicrobial activities, antioxidant activities, immunomodulation, and suppression of tumor growth and metastasis [6-9]. In addition, lactoferrin has potential use in the treatment of osteoarthritis and other inflammatory 
diseases [10,11]. These factors make it a supplementary functional food and stimulate increasing interest in exploiting the therapeutic value of lactoferrin [8,12].

Lactoferrin is widely distributed in mucosal secretions of mammalian species, such as tears, saliva, and bile, and is in highest abundance in milk and colostrum [6]. The lactoferrin found in camel milk and colostrum is at concentrations of $0.18-2.48 \mathrm{mg} \mathrm{mL}^{-1}$ and $0.59-5.10 \mathrm{mg} \mathrm{mL}^{-1}[13,14]$, respectively, higher than in cows, goats, and buffaloes $[13,15]$. Camel milk was frequently reported to have higher antimicrobial activity and biological value than those of bovine milk $[15,16]$. It is significantly more heat resistant than cow and buffalo milk lactoferrins [15]. The annual output of camel milk is about 2.9 million tons all over the world [17], and camel milk is one of the main components of the human diet in many parts of the world. However, the concentration of camel lactoferrin is period-dependent and is significantly dependent on season $[13,14]$. The concentration changes of lactoferrin may affect the nutritional value and biological functions of camel milk. For nutritional assessment and quality control, it is necessary to establish reliable analytical methods for the determination of lactoferrin in camel milk.

Some analytical techniques such as spectrophotometry [3], high-performance liquid chromatography (HPLC) [13], and immunochemical assay $[13,15,18]$ have been used for the determination of camel lactoferrin. Spectrophotometry and HPLC methods have inherently poor precision and insufficient resolution, because the different forms of lactoferrin (native, apo-, and holo-lactoferrin) may affect their physicochemical properties such as color, particle charge, and rheological behavior [19]. The immunodiffusion technique has the advantages of easy operation and simple instrumentation, but this method has poor precision. Furthermore, the preparation of antigen and antibody is complicated and expensive, and it is not suitable for the testing of large quantities of samples. Enzyme-linked immunosorbent assay (ELISA) is more selective and sensitive; the ELISA kit has been used for bovine lactoferrin determination [20-22]. The commercially available ELISA kit is not suitable for camel lactoferrin determination, however, because the target protein cannot bind the antigen and antibody in the kit. To our knowledge, there is no simple, robust, and accurate detection method that can be used for the rapid quantification of camel lactoferrin.

Liquid chromatography-tandem mass spectrometry (LC-MS/MS), a popular detection method that is emerging because of its high sensitivity, specificity, and reliability, has increasingly contributed to expanding protein analysis based on entire proteins or tryptic peptides. Some major proteins in bovine milk such as casein, beta-lactoglobulin, and alpha-lactalbumin have been investigated by LC-MS/MS method [23-25]. A similar analytical method was also developed for the determination of bovine lactoferrin in dairy products [12]. However, it is not suitable for camel lactoferrin determination because the signature peptide used for MS/MS analysis represents bovine lactoferrin, and the amino acid sequence in camel lactoferrin is not the same [3].

The aim of this study was to develop and validate a simple, robust, and accurate method for the rapid quantification of camel lactoferrin by LC-MS/MS. The camel lactoferrin was purified by heparin affinity chromatography and then digested with trypsin. A signature peptide having higher response and ionization efficiency is selected as the representative of camel lactoferrin protein. The actual isotopically labeled internal standard of the lactoferrin was synthesized according to the tryptic winged peptide. Subsequent analysis was performed by LC-MS/MS in the multiple reaction monitoring (MRM) mode under positive ionization mode. The contents of camel lactoferrin were calculated on basis of the equimolar relationship between lactoferrin protein and lactoferrin signature peptide. Finally, the validated method was applied to determine the camel lactoferrin contents of ten camel milk samples.

\section{Results and Discussion}

\subsection{Purification of Camel Lactoferrin}

Since lactoferrin can bind anionic compounds such as heparin and DNA, these materials have been used to purify lactoferrin [7]. The use of heparin-Sepharose affinity chromatography for the 
purification of lactoferrin from human whey was first described by Bläckberg and Hernell [26], and this method was used for the purification of lactoferrin from bovine milk [27]. On the basis of the elution profile of human or bovine lactoferrin eluted from a heparin-Sepharose column [26,27], the elution gradient of $1.0 \mathrm{M}$ sodium chloride in $10 \mathrm{mM}$ sodium phosphate buffer ( $\mathrm{pH} 7.0$ ) were used to remove impurities and to collect camel lactoferrin. The purified camel lactoferrin was analyzed by SDS-PAGE. The single protein band with an estimated molecular mass of $75 \mathrm{kDa}$ was apparent, indicating that the purification of camel lactoferrin was accomplished (Figure 1); the purified lactoferrin was used for subsequent research.

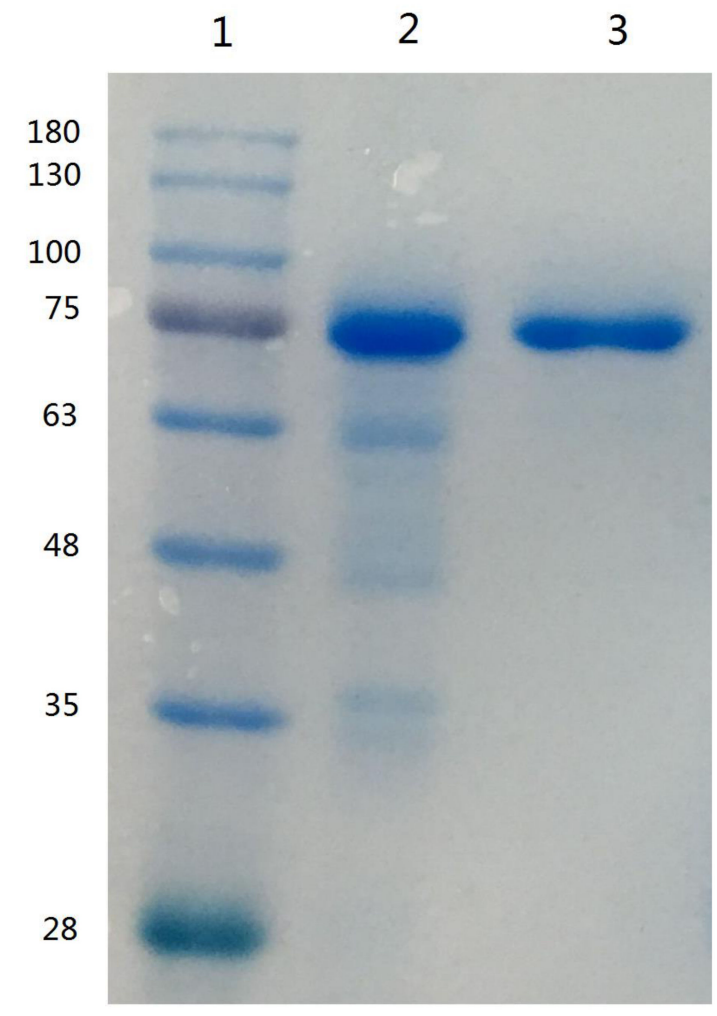

Figure 1. SDS-PAGE of camel lactoferrin obtained from camel milk. Lane 1, molecular weight standards; lane 2, lactoferrin from bovine milk; lane 3, purified camel lactoferrin.

\subsection{Selection and Synthesis of Signature Peptide Standard for Camel Lactoferrin}

For the development of an MRM-based quantitative method for the determination of camel lactoferrin, it is crucial to choose a suitable signature peptide representing camel lactoferrin. Factors such as specificity of amino acid sequences, high efficiency of ionization, strong intensity of MS signal, and prevention of contamination with susceptible amino acid such as cysteine and methionine are essential requirements in the selection of signature peptides [12,25]. Trypsin, which is the commonly used protease for protein digestion and tryptic peptides, tends to be doubly charged. The specific peptides for camel lactoferrin were chosen by comparing the theoretical and endogenous peptides from tryptic camel lactoferrin.

The complete amino acid sequence of camel lactoferrin has been studied and is available in the publicly accessible protein database [3]. The theoretical tryptic peptide of camel lactoferrin was obtained by computational prediction using Waters Biolynx software. The endogenous tryptic peptides were acquired by analysis of the tryptic digests of purified camel lactoferrin and camel milk. By UHPLC-Q-TOF analysis and sequence database search, the peptide DVTVLDNTDGK corresponding to residues 545-555 of camel lactoferrin was selected and synthesized as specific biomarkers of camel lactoferrin because of its specificity, high signal intensity, and sensitivity. The candidate peptide was doubly charged with $\mathrm{m} / \mathrm{z}$ of 588.7 , which is in good agreement with the 
theoretical values. The proposed glycosylation sites in camel lactoferrin were $\mathrm{Asn}^{233}, \mathrm{Asn}^{366}, \mathrm{Asn}^{518}$, and $\mathrm{Asn}^{575}$ [3], and selection of peptide avoided the above four sites. Mass transitions were selected as $m / z 588.7 \rightarrow 649.2$ and $m / z 588.7 \rightarrow 762.5$ from the production ion mass spectra of the synthetic peptide DVTVLDNTDGK, which correspond to b4 and b5 fragment ions, respectively (Figure 2). The specificity and selectivity of the synthesized peptide DVTVLDNTDGK was confirmed by analyzing the camel milk after trypsin cleavage.

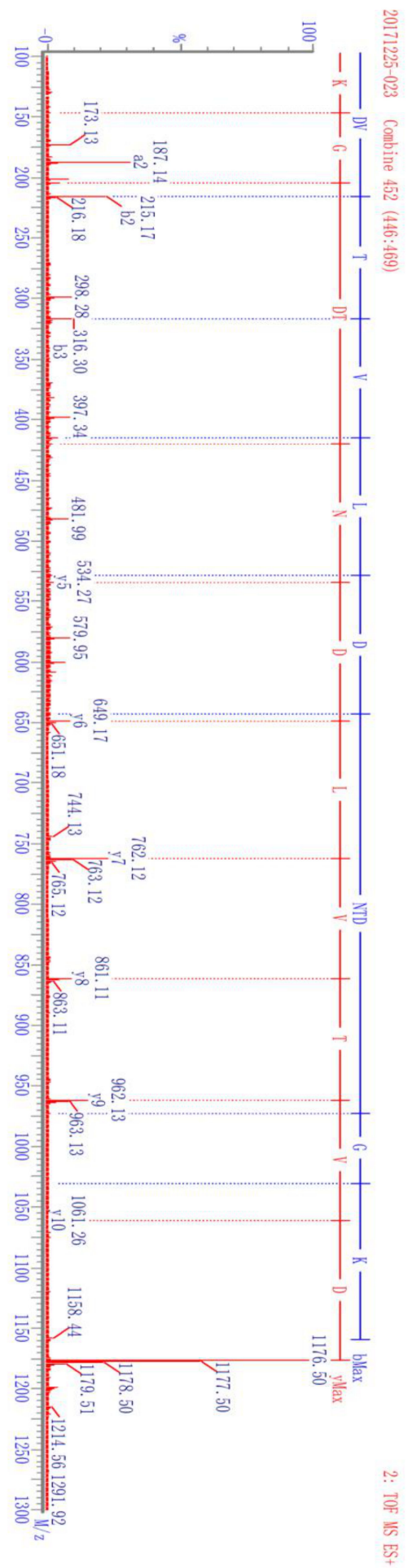

Figure 2. Fragment ions camel lactoferrin signature peptide DVTVLDNTDGK and its corresponding isotope-labeled analog DVTVL*DNTDGK. 


\subsection{Optimization and Synthesis of Isotopically Labeled Signature Peptide and Internal Standard}

The method for the quantitation of camel lactoferrin consisted of a sample preparation procedure to remove lipids and caseins, which was followed by a UHPLC-MS/MS analysis of the whey protein isolate. Since casein is the major protein in camel milk, comprising about 52-87\% of the total proteins [28], removal of casein can prevent its interference in the process of tryptic digestion and then reduce the usage of trypsin and improve the efficiency of enzyme digestion. The recovery of the isolation procedure and proteolytic rate were variable between samples and experiments. Furthermore, the ionization efficiency and the presence of other peptides and matrix components tend to affect the accuracy of this method. In order to minimize the isolation recovery, ionization efficiency, and digestion variability, a winged peptide was used as internal standard. The sequence of the winged peptide is DVAFVKDVTVL*DNTDGKNTEQWAK. It is composed of a stable isotope-labeled signature peptide and six or seven amino acid residues along with the sequence of camel lactoferrin at each end. The sequence of the stable isotope-labeled signature peptide is DVTVL ${ }^{*}$ DNTDGK. There is only one isotope-labeled amino acid in the signature peptide and internal peptide, but it is sufficient to distinguish the isotope-labeled one from its native counterpart by MS via a 7 Da mass shift. In addition, it can lower the cost of synthesis of isotopically labeled internal standard and signature peptide. A similar approach with one isotopically labeled amino acid in signature peptide and internal peptide has been applied to measure phosphoproteins from cell lysates and thyroglobulin in serum and plasma $[29,30]$. The stable isotope-labeled peptide is chemically identical to its native counterpart formed by proteolysis, and its mass transitions were optimized as $\mathrm{m} / \mathrm{z} 592.4 \rightarrow 649.1$ and $\mathrm{m} / \mathrm{z} 592.4 \rightarrow$ 769.4 from the product ion mass spectra, which correspond to b4 and b5 fragment ions, respectively (Figure 2). The signature peptide, stable isotope-labeled signature peptide of camel lactoferrin, showed similar chromatographic performance and good linear response during the UHPLC-MS/MS analysis (Figure 3). The tryptic digestion efficiency of camel lactoferrin and the internal standard were evaluated using the corresponding tryptic amount and compared with the known amount of camel lactoferrin or the internal standard. The digestion efficiency was more than $94.3 \%$ and $93.8 \%$ for camel lactoferrin and its synthetic internal standard, respectively, when they were spiked into the mobile phase. The consistency of digestion efficiency indicated that the synthetic internal standard could mimic the analytical behavior of intact camel lactoferrin.

\subsection{Method Validation}

\subsubsection{Specificity}

The specificity of the signature peptide was assessed by online BLAST search in UniProt (www. uniprot.org) and NCBI (www.ncbi.nlm.nih.gov). The results of BLAST search show that the amino sequence of signature peptide only exists in lactoferrin of camel milk. When human milk, bovine milk, buffalo milk, and goat milk were analyzed by UHPLC-MS/MS, ion pairs of $588.7 \rightarrow 649.2$ and m/z 588.7 $\rightarrow 762.5(\mathrm{~m} / \mathrm{z})$ were not found in these samples. The analytical results further confirm the specificity of the signature peptide and the established method. Comparison of the retention time of the synthetic peptide standards and the selected signature peptide from tryptic samples showed that both of them had a sharp and symmetric peak at $4.09 \pm 0.02 \mathrm{~min}$. All of these results indicated the specificity of the signature peptide for camel lactoferrin.

\subsubsection{Linearity, Sensitivity, and Repeatability}

The method exhibited good linearity between the area ratio $y$ (analyte to internal standard) versus the concentration ratio $x$ (analyte to internal standard) in the range of 10-500 $\mathrm{nM}$. The typical linear regression equation was $y=0.1176 x-0.00288$. The correlation coefficient $(r)$ of the standard curve was greater than 0.999 . The LOD and LOQ were $3.8 \mathrm{mg} \mathrm{kg}^{-1}$ and $11.0 \mathrm{mg} \mathrm{kg}^{-1}$, respectively, which were estimated to be the lowest concentration corresponding to 3 and 10 times the S/N ratio, respectively. This result suggested that the proposed method was sensitive enough for detecting camel lactoferrin 
in camel milk. The repeatability expressed as the RSD was obtained from the results from multiple measurements $(n=6)$ of each sample. The RSD was 3.2-7.8\%, which demonstrated that the developed UHPLC-MS/MS method was reproducible.

\section{- Signature peptide \\ - Is otope-labeled analog}

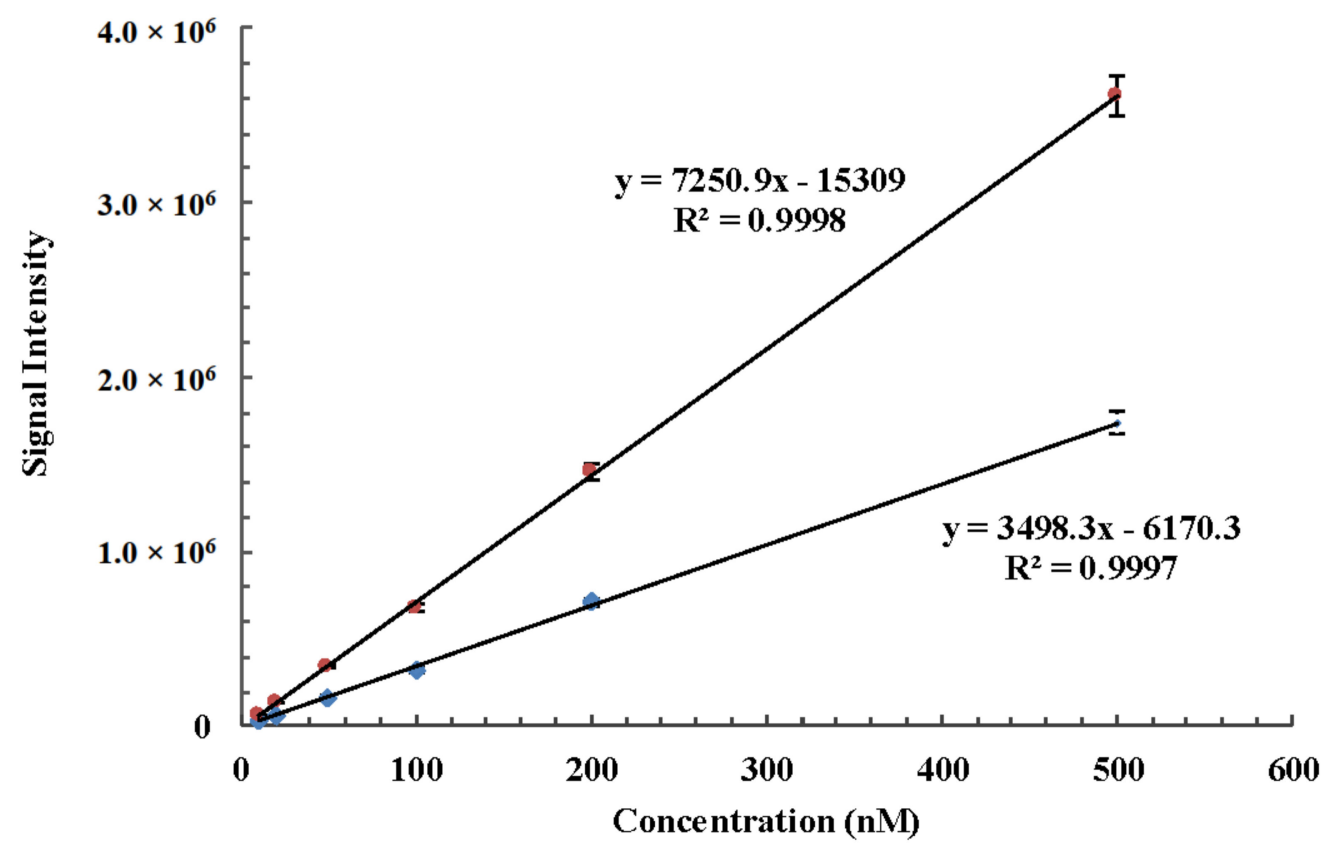

Figure 3. Linear response of camel lactoferrin signature peptide DVTVLDNTDGK and its corresponding isotope-labeled analog DVTVL*DNTDGK during the UHPLC-MS/MS analysis.

\subsubsection{Recovery and Precision}

A recovery experiment was performed to evaluate the accuracy of the method. Intraday and interday variations, as well as RSDs of the peak areas, were calculated to express the precisions. Table 1 provides mean recoveries and RSDs of the analytes. The spiking recovery rates were $74.5-103.6 \%$ with the RSD of $6.4-7.7 \%$. The RSDs of intra- and interday precision were determined as $5.5-8.9 \%$ and 3.3-10.1\%, respectively. All of the results demonstrated that the current method had good recovery and precision, and that it was able to satisfy the requirements for the quantification of camel lactoferrin in camel milk.

Table 1. Spiked recovery of the UHPLC-MS/MS method for determination of camel lactoferrin $(n=6)$.

\begin{tabular}{|c|c|c|c|c|}
\hline $\begin{array}{l}\text { Original Level } \\
(\mathrm{mg} / \mathbf{1 0 0} \mathrm{g})\end{array}$ & $\begin{array}{l}\text { Spiked Level } \\
\text { (mg/100 g) }\end{array}$ & $\begin{array}{l}\text { Determined Level } \\
\quad(\mathrm{mg} / 100 \mathrm{~g})\end{array}$ & Recovery Rate (\%) & RSD \% \\
\hline $6.2 \pm 0.5$ & 6.0 & $10.6 \pm 0.3$ & $74.5 \pm 5.7$ & 7.7 \\
\hline $29.3 \pm 1.0$ & 30.0 & $60.4 \pm 2.3$ & $103.6 \pm 7.6$ & 7.3 \\
\hline $65.1 \pm 4.5$ & 60.0 & $123.4 \pm 3.6$ & $97.1 \pm 6.0$ & 6.4 \\
\hline
\end{tabular}

\subsection{Method Application}

The validated method was applied to determine the lactoferrin in 10 samples collected from Xinjiang Province. All samples were digested with trypsin and subjected to UHPLC-MS/MS analysis according to the aforementioned procedures. The selected signature peptide from camel lactoferrin and its isotope-labeled analog from spiked internal standard were successfully detected in the tryptic 
cleavage products of all samples (a typical chromatogram is shown in Figure 4). The amounts of camel lactoferrin in liquid milk were $62-651 \mathrm{mg} \mathrm{kg}^{-1}$, consistent with literature reports $[13,14]$. The lactoferrin is generally considered as particularly rich in colostrum or milk from camel. An extremely high lactoferrin content of $5.10 \mathrm{mg} \mathrm{mL}^{-1}$ was reported in one camel colostrum sampled $2 \mathrm{~d}$ after parturition, as compared with about $0.50 \mathrm{mg} \mathrm{mL}^{-1}$ in bovine colostral milk [13]. The concentration of lactoferrin significantly decreased after 8 days of milking, whereas the values were still higher than those in bovine milk [18]. The variability of lactoferrin in camel milk was determined by the lactation stage, species of camel, as well as seasonal and geographic conditions.

\section{Materials and Methods}

\subsection{Materials}

Ammonium bicarbonate $\left(\mathrm{NH}_{4} \mathrm{HCO}_{3}\right)$, calcium chloride $\left(\mathrm{CaCl}_{2}\right)$, sodium chloride $(\mathrm{NaCl})$, sodium hydroxide $(\mathrm{NaOH})$, disodium hydrogen phosphate $\left(\mathrm{Na}_{2} \mathrm{HPO}_{4}\right)$, and acetic acid, which were of analytical grade, were purchased from Sinopharm Chemical Reagent Co., Ltd. (Shanghai, China). Lactoferrin from bovine milk (>85\%), Tris (2-carboxyethyl) phosphine hydrochloride (TCEP), and iodoacetamide (IAA) were obtained from Sigma-Aldrich (St. Louis, MO, USA). Sequencing-grade modified trypsin was from Promega Corporation (Madison, WI, USA). Methanol, acetonitrile, and formic acid of HPLC grade were purchased from Fisher Chemicals (Fair Lawn, NJ, USA). Ultrapure water was obtained from a Milli-Q gradient water system (Millipore, Bedford, MA, USA). HiTrap ${ }^{T M}$ Heparin HP was obtained from GE Healthcare Bio-Science AB (Uppsala, Sweden). Ultracel ${ }^{\circledR}-50 \mathrm{~K}$ centrifugal filters were obtained from Merck Millipore Ltd. (Tullagreen, Carrigtwohill, Ireland).

\subsection{Synthetic Peptide Standards}

The signature peptide DVTVLDNTDGK (corresponding to amino acid residues 545-555 of camel lactoferrin), stable isotope-labeled signature peptide DVTVL*DNTDGK, and internal standard DVAFVKDVTVL*DNTDGKNTEQWAK were synthesized by Sangon Biotech (Shanghai) Co., Ltd. (Shanghai, China). The stable isotope-labeled ${ }^{13} \mathrm{C},{ }^{15} \mathrm{~N}$-Fmoc-D-leucine gave a total molecular mass shift of $7 \mathrm{Da}$ from the nonlabelled peptide. All the peptide standards were synthesized with purity of more than $95 \%$.

\subsection{Purification of Camel Lactoferrin}

For the purification of camel lactoferrin, the camel milk was defatted by centrifugation at $4000 \times g$ for $20 \mathrm{~min}$ at $4{ }^{\circ} \mathrm{C}$. The skim milk was adjusted to $\mathrm{pH} 4.6$ with acetic acid at $20^{\circ} \mathrm{C}$ and kept at $4{ }^{\circ} \mathrm{C}$ for $30 \mathrm{~min}$, and then it was centrifuged at $8000 \times g$ for $30 \mathrm{~min}$ to remove casein. The suspension was transferred to a centrifugal filter (Ultracel ${ }^{\circledR}-50 \mathrm{~K}$ ) and centrifuged at $3000 \times g$ for $60 \mathrm{~min}$ at $4{ }^{\circ} \mathrm{C}$ to remove low molecular weight proteins (less than $50 \mathrm{kDa}$ ). The residual solution was adjusted to $\mathrm{pH}$ 7.0 and then applied to a heparin affinity column (HiTrap ${ }^{\mathrm{TM}}$ Heparin HP) equilibrated with $10 \mathrm{mM}$ sodium phosphate solution ( $\mathrm{pH} 7.0$ ). The elution gradient was $0.5 \mathrm{M}$ sodium chloride in $10 \mathrm{mM}$ sodium phosphate buffer ( $\mathrm{pH} 7.0$ ) to remove impurities, and $2.0 \mathrm{M}$ sodium chloride in $10 \mathrm{mM}$ sodium phosphate buffer ( $\mathrm{pH}$ 7.0) for camel lactoferrin. All buffers were prepared with deionized water. 


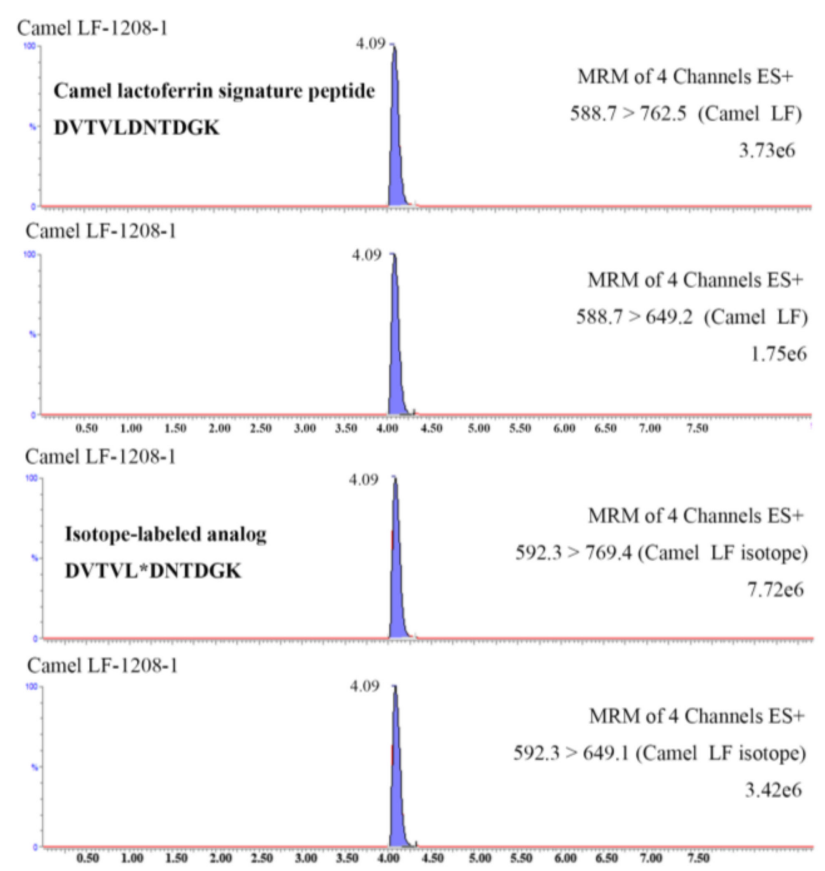

Figure 4. UHPLC-MS/MS chromatograms of camel lactoferrin signature peptide DVTVLDNTDGK (B) and its corresponding isotope-labeled analog DVTVL*DNTDGK in a tryptic dairy sample.

\subsection{Electrophoresis}

Sodium dodecyl sulfate-polyacrylamide gel electrophoresis (SDS - PAGE) was performed with a $5 \%$ stacking gel and a $12 \%$ separating gel containing $0.1 \%$ SDS, followed by running in $0.125 \mathrm{M}$ Tris- $\mathrm{HCl}$ at $\mathrm{pH} 6.8$ and $0.38 \mathrm{M}$ Tris- $\mathrm{HCl}$ buffers at $\mathrm{pH} 8.8$, respectively. The proteins were stained with Coomassie Brilliant Blue 250 and destained with a methanol (30\%) and acetic acid (7\%) solution. The absorbency measured at $280 \mathrm{~nm}$ and an extinction coefficient of $84540 \mathrm{M}^{-1} \mathrm{~cm}^{-1}$ were used to calculate the concentration of camel lactoferrin [3].

\subsection{Preparation of Tryptic Hydrolysates}

Prior to tryptic hydrolysis, the camel milk was adjusted to $\mathrm{pH} 4.6$ with acetic acid, and then it was centrifuged at $8000 \times \mathrm{g}$ for $30 \mathrm{~min}$ to remove casein and fat. Aliquots of $100 \mu \mathrm{L}$ of whey were spiked with $100 \mu \mathrm{L}$ of $1 \mu \mathrm{M}$ stable isotope-labeled internal standard DVAFVKDVTVL ${ }^{*}$ DNTDGKNTEQWAK and then mixed with $180 \mu \mathrm{L}$ of $50 \mathrm{mM} \mathrm{NH}_{4} \mathrm{CO}_{3}$. The mixtures were reduced by adding $15 \mu \mathrm{L}$ of $500 \mathrm{Mm}$ TCEP solution at $50{ }^{\circ} \mathrm{C}$ for $30 \mathrm{~min}$. An alkylation was performed in the presence of $45 \mu \mathrm{L}$ of $500 \mathrm{mM}$ IAA solution at room temperature for $30 \mathrm{~min}$ in the dark. Subsequently, $10 \mu \mathrm{L}$ of $100 \mathrm{mM} \mathrm{CaCl}_{2}$ solution and enough trypsin was added, and then it was incubated at $37^{\circ} \mathrm{C}$ overnight. The reaction was terminated by the addition of $10 \mu \mathrm{L}$ of formic acid, and then the mixture was diluted to $1 \mathrm{~mL}$ and with ultrapure water. After the filtrate was passed through a $0.22 \mathrm{~mm}$ nylon filter, it was analyzed by LC-MS/MS.

\subsection{Liquid Chromatography}

Chromatographic separation was performed on an ACQUITY Ultra Performance Liquid Chromatography System (Waters, Milford, MA, USA) consisting of a cooled autosampler and a column oven. The system was equipped with a Waters Acquity UPLC BEH C18 column (100 mm × $2.1 \mathrm{~mm}$ I.D., $1.7 \mu \mathrm{m}, 300 \AA$ ). Mobile phase A was Milli-Q water containing $0.1 \%$ ammonia, and mobile phase B was acetonitrile. A binary gradient system with a flow rate of $0.3 \mathrm{~mL} \mathrm{~min}{ }^{-1}$ was established. The gradient steps were as follows: $10 \%$ B for 0-1 min, linear increase from $10 \%$ to $90 \%$ B for 1-4 min, and holding for $6.5 \mathrm{~min}$; and $10 \% \mathrm{~B}$ for $6.5-7 \mathrm{~min}$ followed by re-equilibration of the column for $3 \mathrm{~min}$. The injection 
volume was $5 \mu \mathrm{L}$, and the total run time for each injection was $7 \mathrm{~min}$. The effluent from the UHPLC system was directed into the electrospray ion (ESI) source of the mass spectrometer (MS).

\subsection{Mass Spectrometry}

Search and identification of signature peptide for camel lactoferrin was performed on a Xevo G2-S QTof mass spectrometer equipped with ESI source (Waters, Milford, MA, USA). The instrument was operated in the electrospray positive ion $\left(\mathrm{ESI}^{+}\right)$mode. The conditions were as follows: capillary voltage of $3.0 \mathrm{kV}$, sampling cone voltage of $30 \mathrm{~V}$, extraction cone voltage of $4.0 \mathrm{~V}$, source temperature of $100{ }^{\circ} \mathrm{C}$, desolvation temperature of $450{ }^{\circ} \mathrm{C}$, cone gas of $50 \mathrm{~L} \mathrm{~h}^{-1}$ undefined nitrogen; and desolvation gas of $800 \mathrm{~L} \mathrm{~h}^{-1}$ nitrogen. The data acquired in MSE continuum mode were processed using MassLynx 4.1 (Waters) and analyzed using ProteinLynx Global Server version 2.5 software (PLGS 2.5, Waters). The search parameters were trypsin enzyme, fixed modification site of carboxymethyl, and a maximum of one missed cleavage. The specificity of the signature peptide selected for camel lactoferrin was confirmed by BLAST program in the National Center for Biotechnology Information (NCBI) database.

A Xevo TQ-S triple quadrupole mass spectrometer (Waters, Milford, MA, USA) equipped with ESI source was used for all quantitative data. Sample introduction and ionization was done in the positive mode between 200 and $1200 \mathrm{~m} / \mathrm{z}$. The capillary voltage was $3.50 \mathrm{kV}$ and the cone voltage was $15 \mathrm{~V}$. Nitrogen was used as desolvation gas at a flow rate of $850 \mathrm{~L} \mathrm{~h}^{-1}$. The desolvation gas temperature was $500^{\circ} \mathrm{C}$, and the source temperature was $130^{\circ} \mathrm{C}$. Argon was used as collision gas at the pressure of $3 \times 10^{3}$ mbar. Mass transitions monitored in the method were $\mathrm{m} / \mathrm{z} 588.7 \rightarrow 762.5,588.7 \rightarrow 649.2$ for the peptide DVTVLDNTDGK, and 592.3 $\rightarrow 769.4,592.3 \rightarrow 649.2$ for the peptide DVTVL*DNTDGK. Data were acquired in MRM mode, and the scheduled MRM function was used as the acquisition method to ensure enough acquisition points (at least 12 points for each peak).

\subsection{Method Validation}

The following parameters were studied for method validation: Specificity, detection (LOD), quantification (LOQ) limits, linearity, recovery, precision, and accuracy. The specificity was demonstrated by comparing the retention time of the synthetic signature peptide standard and natural peptide from tryptic samples. The method LOD and LOQ at which the signal-to-noise ratio had to be at least 3 for the LOD and 10 for the LOQ were determined. For the determination of range and linearity of the method, six signature peptide standards containing a fixed concentration of stable isotope-labeled signature peptide in the range of 10-500 $\mathrm{nM}$ were prepared and analyzed by the internal standard method. The recovery of the present method was evaluated by employing the standard addition method. To evaluate the recoveries of the preparation method, purified camel lactoferrin was spiked into fresh camel milk at low, medium, and high concentrations. The recovery was calculated according to the following equation: Recovery $(\%)=($ measured concentration-the original level)/spiked concentration $\times 100 \%$. Intraday and interday precision and accuracy of the method were studied. Intraday precision was determined by analyzing one sample six times in succession on the same day. For interday precision, the same samples were prepared and determined on five different days. Precision was calculated as RSD in percentage.

\section{Conclusions}

In this study, we developed and validated a UHPLC-MS/MS method for the quantitative determination of camel lactoferrin on the basis of the signature peptide derived from the tryptic hydrolysates of camel lactoferrin. The method has two steps: The sample preparation procedures, which include the addition of an isotopically labeled peptide as internal standard followed an enzymatic digestion with trypsin, and the determination of camel lactoferrin by UHPLC-MS/MS analysis. The signature peptide was selected by comparing the endogenous and theoretical peptides from tryptic camel lactoferrin. The specificity, sensitivity, repeatability, and precision of this method demonstrated that the current method was able to satisfy the requirements for the quantification of camel lactoferrin 
in camel milk. The present method was successfully applied to determine lactoferrin in camel milk and whole milk powder. To the best of our knowledge, this is the first time that camel lactoferrin was quantitatively analyzed through a UHPLC-MS/MS method.

Author Contributions: Conceptualization, L.D. and Z.L.; Methodology, E.X. and L.C. (Ling Chen); Formal Analysis, L.C. (Lu Chen); Investigation, D.G.; Resources, H.F.; Writing-Original Draft Preparation, X.L.; Writing-Review \& Editing, X.L.; Project Administration, D.G. and L.D.

Funding: This work was supported by Agricultural Scientific and Technological Innovation Project of the Shandong Academy of Agricultural Sciences (Grant No.CXGC2017A03).

Acknowledgments: The author would like to thank ANPEL Laboratory Technologies (Shanghai) Inc. for its support of this experimental consumable.

Conflicts of Interest: We declared that there was no conflict of interest in our paper.

\section{References}

1. Sorensen, M.; Sorensen, S.P.L. The proteins in whey. C. R. Trav. Lab. Carlsberg 1939, 23, 55-99.

2. Johanson, B. Isolation of an iron-containing red protein from milk. Acta Chem. Scand. 1960, 14, 510-512. [CrossRef]

3. Stefan, R.; Kappeler, M.A.; Farah, Z.; Puhan, Z. Sequence analysis of camel (Camelus dromedarius) lactoferrin. Int. Dairy J. 1999, 9, 481-486.

4. Levay, P.F.; Viljoen, M. Lactoferrin: A general review. Haematologica 1995, 80, 252-267. [PubMed]

5. Moore, S.A.; Anderson, B.F.; Groom, C.R.; Haridas, M.; Baker, E.N. Three-dimensional structure of diferric bovine lactoferrin at 2.8 A resolution. J. Mol. Biol. 1997, 274, 222-236. [CrossRef] [PubMed]

6. González-Chávez, S.A.; Arévalo-Gallegos, S.; Rascón-Cruz, Q. Lactoferrin: Structure, function and applications. Int. J. Antimicrob. Agents 2009, 33, e1-e301. [CrossRef]

7. Wakabayashi, H.; Yamauchi, K.; Takase, M. Lactoferrin research, technology and applications. Int. Dairy J. 2006, 16, 1241-1251. [CrossRef]

8. Habib, H.M.; Ibrahim, W.H.; Schneider-Stock, R.; Hassan, H.M. Camel milk lactoferrin reduces the proliferation of colorectal cancer cells and exerts antioxidant and DNA damage inhibitory activities. Food Chem. 2013, 141, 148-152. [CrossRef] [PubMed]

9. Almehdar, H.A.; El-Baky, N.A.; Alhaider, A.A.; Almuhaideb, S.A.; Alhaider, A.A.; Albiheyri, R.S.; Uversky, V.N.; Redwan, E.M. Bacteriostatic and Bactericidal Activities of Camel Lactoferrins Against Salmonella enterica Serovar Typhi. Probiotics Antimicrob. Proteins 2019. [CrossRef]

10. Rasheed, N.R.A.A.Z. Lactoferrin from Camelus dromedarius Inhibits Nuclear Transcription Factor-kappa B Activation, Cyclooxygenase-2 Expression and Prostaglandin E2 Production in Stimulated Human Chondrocytes. Pharmacogn. Res. 2016, 8, 135-141. [CrossRef]

11. Samarasinghe, R.M.; Kanwar, R.K.; Kanwar, J.R. The effect of oral administration of iron saturated-bovine lactoferrin encapsulated chitosan-nanocarriers on osteoarthritis. Biomaterials 2014, 35, 7522-7534. [CrossRef] [PubMed]

12. Zhang, J.; Lai, S.; Cai, Z.; Chen, Q.; Huang, B.; Ren, Y. Determination of bovine lactoferrin in dairy products by ultra-high performance liquid chromatography-tandem mass spectrometry based on tryptic signature peptides employing an isotope-labeled winged peptide as internal standard. Anal. Chim. Acta 2014, 829, 33-39. [CrossRef] [PubMed]

13. El-Gawad, I.A.; El-Sayed, E.M.; Mahfouz, M.B.; Abd El-Salam, A.M. Changes of Lactoferrin concentration in colostrum and milk from different species. Egypt J. Dairy Sci. 1996, 24, 297-308.

14. Konuspayeva, G.; Faye, B.; Loiseau, G.; Levieux, D. Lactoferrin and Immunoglobulin Contents in Camel's Milk (Camelus bactrianus, Camelus dromedarius, and Hybrids) from Kazakhstan. J. Dairy Sci. 2007, 90, 38-46. [CrossRef]

15. Elagamy, E.I. Effect of heat treatment on camel milk proteins with respect to antimicrobial factors: A comparison with cows' and buffalo milk proteins. Food Chem. 2000, 68, 227-232. [CrossRef]

16. El-Hatmi, H.; Girardet, J.-M.; Gaillard, J.-L.; Yahyaoui, M.H.; Attia, H. Characterisation of whey proteins of camel (Camelus dromedarius) milk and colostrum. Small Rumin. Res. 2007, 70, 267-271. [CrossRef] 
17. FAO. Whole Fresh Camel Milk Production Quantity. Available online: http://www.fao.org/faostat/en/\#data/ QL (accessed on 9 October 2019).

18. El-Hatmi, H.; Levieux, A.; Levieux, D. Camel (Camelus dromedarius) immunoglobulin G, alpha-lactalbumin, serum albumin and lactoferrin in colostrum and milk during the early post partum period. J. Dairy Res. 2006, 73, 288-293. [CrossRef]

19. Bokkhim, H.; Bansal, N.; Grondahl, L.; Bhandari, B. Physico-chemical properties of different forms of bovine lactoferrin. Food Chem. 2013, 141, 3007-3013. [CrossRef]

20. Du, Q.Y.; Lin, D.Q.; Zhang, Q.L.; Yao, S.J. An integrated expanded bed adsorption process for lactoferrin and immunoglobulin G purification from crude sweet whey. J. Chromatogr. 2014, 947-948, 201-207. [CrossRef]

21. Nowak, P.; Spiewak, K.; Brindell, M.; Wozniakiewicz, M.; Stochel, G.; Koscielniak, P. Separation of iron-free and iron-saturated forms of transferrin and lactoferrin via capillary electrophoresis performed in fused-silica and neutral capillaries. J. Chromatogr. A 2013, 1321, 127-132. [CrossRef]

22. Zhang, Y.; Luo, J.; Zhang, S.; Bai, Q.; Li, Z.; Li, Q.; Liu, Y.; Zhang, G.; Ma, G.; Su, Z. Selection of downstream steps by analysis of protein surface property: A case study for recombinant human lactoferrin purification from milk of transgenic cow. Process Biochem. 2015, 50, 1441-1448. [CrossRef]

23. Ren, Y.; Han, Z.; Chu, X.; Zhang, J.; Cai, Z.; Wu, Y. Simultaneous determination of bovine alpha-lactalbumin and beta-lactoglobulin in infant formulae by ultra-high-performance liquid chromatography-mass spectrometry. Anal. Chim. Acta 2010, 667, 96-102. [CrossRef] [PubMed]

24. Lutter, P.; Parisod, V.; Weymuth, H. Development and validation of a method for the quantification of milk proteins in food products based on liquid chromatography with mass spectrometric detection. J. Aoac Int. 2011, 94, 1043-1059. [PubMed]

25. Zhang, J.; Lai, S.; Zhang, Y.; Huang, B.; Li, D.; Ren, Y. Multiple reaction monitoring-based determination of bovine alpha-lactalbumin in infant formulas and whey protein concentrates by ultra-high performance liquid chromatography-tandem mass spectrometry using tryptic signature peptides and synthetic peptide standards. Anal. Chim. Acta 2012, 727, 47-53. [PubMed]

26. Bläckberg, L.; Hernell, O. Isolation of lactoferrin from human whey by a single chromatographic step. Febs Lett. 1980, 109, 180-184. [CrossRef]

27. Al-Mashikhi, S.; Nakai, S. Isolation of Bovine Immunoglobulins and Lactoferrin from Whey Proteins by Gel Filtration Techniques. J. Dairy Sci. 1987, 70, 2486-2492. [CrossRef]

28. Al haj, O.A.; Al Kanhal, H.A. Compositional, technological and nutritional aspects of dromedary camel milk. Int. Dairy J. 2010, 20, 811-821. [CrossRef]

29. Kushnir, M.M.; Rockwood, A.L.; Roberts, W.L.; Abraham, D.; Hoofnagle, A.N.; Meikle, A.W. Measurement of thyroglobulin by liquid chromatography-tandem mass spectrometry in serum and plasma in the presence of antithyroglobulin autoantibodies. Clin. Chem. 2013, 59, 982-990. [CrossRef]

30. Gerber, S.A.; Rush, J.; Stemman, O.; Kirschner, M.W.; Gygi, S.P. Absolute quantification of proteins and phosphoproteins from cell lysates by tandem MS. Proc. Natl. Acad. Sci. United States Am. 2003, 100, 6940-6945. [CrossRef]

Sample Availability: Samples of the compounds are not available from the authors.

(C) 2019 by the authors. Licensee MDPI, Basel, Switzerland. This article is an open access article distributed under the terms and conditions of the Creative Commons Attribution (CC BY) license (http://creativecommons.org/licenses/by/4.0/). 